UCRL-ID-118660

\title{
Ceramic Package Fabrication for YMP Nuclear Waste Disposal
}

\author{
Keith Wilfinger
}

August 1994

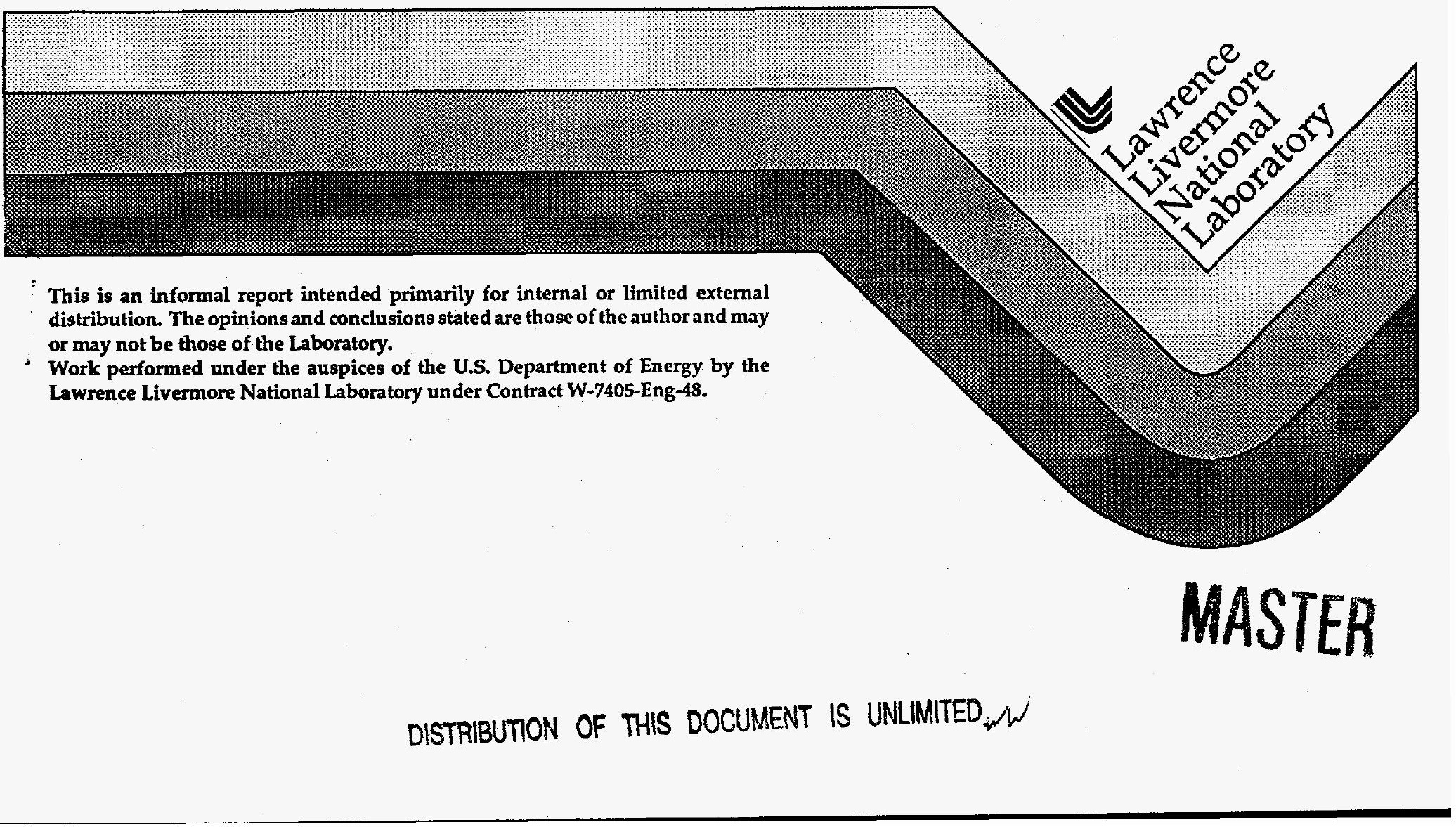




\section{DISCLAIMER}

This document was prepared as an account of work sponsored by an agency of the United States Government. Neither the United States Government nor the University of California nor any of their employees, makes any warranty, express or implied, or assumes any legal liability or responsibility for the accuracy, completeness, or usefulness of any information, apparatus, product, or process disclosed, or represents that its use would not infringe privately owned rights. Reference herein to any specific commercial products, process, or service by trade name, trademark, manufacturer, or otherwise, does not necessarily constitute or imply its endorsement, recommendation, or favoring by the United States Government or the University of California. The views and opinions of authors expressed herein do not necessarily state or reflect those of the United States Government or the University of California, and shall not be used for advertising or product endorsement purposes.

This report has been reproduced directly from the best available copy.

Available to DOE and DOE contractors from the Office of Scientific and Technical Information

P.O. Box 62, Oak Ridge, TN 37831

Prices available from (615) 576-8401, FTS 626-8401

Available to the public from the National Technical Information Service

U.S. Department of Commerce

5285 Port Royal Rd.,

Springfield, VA 22161 


\section{DISCLAIMER}

Portions of this document may be illegible in electronic image products. Images are produced from the best available original document. 


\section{Ceramic Package Fabrication for YMP Nuclear Waste Disposal Keith Wilfinger $\times 35643 \quad$ L-369}

Introduction

The purpose of this work is to develop alternate materials/design concepts to metal barriers for the Nevada Nuclear Waste Storage Investigations Project. There is some potential that site conditions may prove to be too aggressive for successful employment of the metal alloys under current consideration or that performance assessment models will predict metal container degradation rates that are inconsistent with the goal of substantially complete containment included in the NRC regulations. In the event that the anticipated lifetimes of metal containers are considered inadequate, alternate materials (i.e. ceramics or ceramic/metal composites) will be chosen due to superior corrosion resistance.

This document was prepared using information taken from the open literature, conversations and correspondence with vendors, news releases and data presented at conferences to determine what form such a package might take. Most of what follows represents an amalgam of opinions and general beliefs held in the ceramic industry. Opinions were by no means unanimous. Indeed, many suggestions were made with which the author does not agree. Generally however, greater credence was given to those who said "we can do this by the following method" rather than "it can't be done." This discussion presents some ceramic material selection criteria, alternatives for the materials which might be used and alternatives for potential fabrication routes. This includes "stand alone" ceramic components and ceramic coatings/linings for metallic structures.

A list of companies providing verbal or written information concerning the production of ceramic or ceramic lined waste containers appears at the end of this discussion. Representatives of several of these firms expressed doubt as to the ability of the industry as a whole to produce the required large ceramic containers at all. Others suggested it could not be done without significant additions to existing facilities and technology, a process which could take years. This is in addition to several years of projected development time and no guarantee of positive results. Others simply declined to involve themselves on the basis that the project was too far outside their expertise and/or normal working limits of scale. Representatives of a small group of companies showed enthusiasm for the concept, based primarily on the possibility of adapting their present product lines and processes to the construction of ceramic or ceramic lined waste containers. This group includes Corning Glass, Coors Ceramics, Sauereisen, Ipsen, The Ceramic Coating Company, Plasmadyne, Babcock and Wilcox, Praxaire, Norton and WESGO.

$-1-$

$9 / 23 / 94$

$\mathrm{K}$. Wilfinger 


\section{Background}

Several candidate metals are presently being evaluated for long term container storage of nuclear waste in the proposed Yucca Mountain tuff repository. Metals under study include A516 and A27 steels, high nickel alloys such as Incoloy 825, C-22 and C-4, titanium alloys including Ti 12 and Ti 16, CDA715 (70/30 copper-nickel) and Monel 400 (70/30 nickel-copper) The design of the repository and containers, and properties and test programs for the candidate metals have been presented in a number of places [1-5 among others], and will be described here only in general terms.

The waste packages are to have the nominal form of circular cylinders some 18 feet long by approximately six feet in diameter. The final design is not yet fixed, but must be sufficient to permit efficient storage of a number of complete spent fuel rod assemblies or reasonable quantities of other nuclear waste forms. The outermost layer is the disposal overpack, which provides a corrosion resistant barrier to protect a multi-purpose container (MPC), which in turn holds the waste form. This overpack is distinct from the more expensive re-usable transportation overpack that will be used to deliver waste materials to the repository site. Vitrified or cementitious waste forms may be further enclosed by a pour canister within the MPC. Spent fuel rod assemblies may be separated within the MPC by a space-frame or gridwork to prevent criticality.

Multiple layers in the disposal overpack are possible. It is in the overpack that ceramics are most likely to be useful. The overpack must have a sealable closure that can be completed remotely in a radiation hot cell without thermal damage to the zircalloy cladding on fuel rods stored inside the MPC. There must be some reasonable method to facilitate emplacement. The containers are to be stored end to end in horizontally drilled drifts (tunnels) in the rock of the repository site.

The LLNL design criteria for the waste package and its components were established by Russel et. al. [6] using NRC 10CFR60 and NRC 10CFR71. According to regulation 60.135, "Criteria for the waste package and its components: (a) High-levelwaste package design in general:"

"(2) The design shall include but not be limited to consideration of the following factors: solubility, oxidation/reduction reactions, corrosion, hydriding, gas generation, thermal effects, mechanical strength, mechanical stress, radiolysis, radiation damage, radio nuclide retardation, leaching, fire and explosion hazards, thermal loads and synergistic interactions."

The overpack must be able to survive normal handling, be identifiable and recoverable for at least 50 years after emplacement and provide "substantial containment" for a period of 300 to 1000 years. Beyond this time, the release rate of any of the -2 - 
radioactive species from the barrier system must be less than 1 part in 100,000 per year of the inventory calculated to remain after 1000 years.

It seems likely that one or more of the candidate metals will provide an acceptable combination of strength, corrosion resistance, thermal properties and cost for the intended storage period. On strength considerations alone, the steel and copper alloys are more than adequate [7]. There is some chance that the packages could undergo impact and unbalanced mechanical stresses resulting from partial collapse of the rock in which they are to be emplaced. However, any failure to perform would most probably result from slow degradation, i.e., corrosion or stress corrosion cracking, especially at the welds, which appear to be the weakest link in any package design. Sensitization of steels leading to carbide precipitation and embrittlement is a potential danger after extended periods of time at approximately $300^{\circ} \mathrm{C}$ or higher, which could reasonably be a normal part of the containment environment. This is allowed for in the selection of metal alloys under consideration. Other factors contributing to slow degradation might include ambient moisture, concentrated salts deposited by evaporation of vadose water, gamma radiation and heat due to nuclear decay within the containers [3]. Recently, there has also been considerable concern regarding microbiologically influenced corrosion (MIC) in which metal oxidation can become a direct energy source for microorganisms and/or the metals are attacked by acid waste products produced by their life cycles.

Many available ceramics would be expected to exhibit great stability under the relatively benign environmental conditions predicted for the Yucca Mountain site (radiation not withstanding). Most are not prone to oxidation in a hot steam environment as many metals would be (especially ferrous metals), nor are they likely to be severely affected by deposited salts. Being non-conductors, they are not generally subject to galvanic corrosion, nor are they likely to provide a food source for microbes, since in most cases, activation of the available chemical reactions would require more energy than they provide.

\section{Material/Process Selection Criteria}

The criteria presented by Russel are reasonably comprehensive, but must be applied in consideration of the specific characteristics of ceramic materials. The following are the initial considerations used in selecting ceramics for evaluation as waste container materials for the Yucca Mountain repository.

1) All current ceramic engineering materials are brittle compared with the metals on the candidate list. Ceramics do not undergo measurable plastic deformation under load at the expected repository temperatures. Ceramics can be deformed only fractionally before exceeding their elastic limit, leading to typically catastrophic failure. Fracture strength and $-3-$ 
impact resistance may therefore be considered of greater importance for ceramic packages than for metals which can deform plastically. This suggests that optimum performance will result from use of a metallic overpack for structural strength, lined or coated with a ceramic for stability and long term corrosion resistance.

2) In order to provide resistance to slow crack propagation during long periods under static loading, a high fracture toughness is necessary and maximum loads of less than $1 / 3$ of the ultimate fracture stress should be maintained. Under most conditions, this will be relatively easy to achieve, because large or sudden loads will be the exception rather than the rule. In a combined metal-ceramic package, the metal will be expected to provide support to a corrosion resistant ceramic, due to the metal's high toughness and the ability to deform plastically. The strength of ceramics should not be discounted, however, because of improved material properties and high toughness microstructures developed in recent years, and because the ceramic can be pre-loaded for fracture resistance. Thermal treatments and differences in thermal expansion between components can be used to put a ceramic vessel under compression, thereby making it very resistant to fracture, which is inherently a tensile process. It would then be possible for gaps to open in the metallic portion of the container, without exposing the waste material.

3) Some ceramics are quite porous, depending largely on the specific forming route(s) and temperature(s). The selected material(s) should be essentially fully dense, meaning no connected porosity and crack free. This is necessary to prevent penetration by water and water vapor and escape of gaseous products of nuclear decay. Water in the nuclear waste package can dissolve radioactive solids which might then diffuse out of the package and into the local environment. Water could also be hydrolyzed by gamma radiation, possibly leading to the development of explosive concentrations of hydrogen gas. By packaging a dry product and preventing penetration or generation of water, transport of radionuclide species becomes impossible. Generally, if a material is at $94 \%$ of theoretical density or greater, the porosity is isolated rather than continuous. Even isolated porosity should be avoided however, because of its small adverse affect on heat transfer and its much larger adverse effect on mechanical properties.

4) The chosen material(s) must provide a suitable barrier to the diffusion of water and radionuclides. Any joints or closures should provide similar protection if different in character from the rest of the containment barrier. The number of such joints and closures should be minimized, since each represents a potential weak spot in the barrier system.

5) The selected material(s) should not be subject to oxidation or significant chemical corrosion, nor to decomposition in the expected repository environment. It (they) should not be significantly reactive with either the containment surroundings or the radionuclides $-4$ 
being contained. A rather large group of ceramic materials meets this criterion, but simplifying the chemistry of the material selected should be an aid to proving it to the satisfaction of licensing requirements. This suggests that a ceramic with a simple formulation, natural analogs and only a single continuous phase should be used in preference to materials with more complex compositions and/or structures.

6) Since radioactive wastes are self heating, the selected packaging material(s) should have adequate thermal conductivity to maintain minimal temperatures within the waste package, when used in a form that provides sufficient mechanical strength. Maximum permitted storage temperatures are $500^{\circ} \mathrm{C}$ for DHLW glass, $400^{\circ} \mathrm{C}$ for CHLW glass and $350^{\circ} \mathrm{C}$ for spent fuel [8]. Due to wide variability in the heat transfer of ceramics as a function of structure, a relatively thin ceramic coating is likely to be preferable to a larger structural unit.

7) The selected material(s) must be fabricated in the desired form using conventional techniques or by a reasonable adaptation of existing technology. It must be remembered that fully dense monolithic ceramics in the required sizes are presently uncommon due to the lack of general demand as well as the high cost of development. Further, with only a few exceptions, conventional welding techniques are not applicable to ceramics because of their brittleness and susceptibility to thermal shock.

8) Although cost is not among the primary selection criterion per se, it certainly must be considered. Given sufficient time and investment, any single object can probably be produced, but the process must be economically and technically reasonable for manufacturing large numbers of parts.

\section{Candidate Ceramics}

Although the range of possible ceramics is quite large, a relatively few materials offer clear cut manufacturing advantages. The preferred selections for monolithic ceramics in this context are alumina $\left(\mathrm{Al}_{2} \mathrm{O}_{3}\right)$, titania $\left(\mathrm{TiO}_{2}\right)$, partially stabilized zirconia (PSZ) and silicon carbide $(\mathrm{SiC})$, because of their excellent chemical and reasonable mechanical properties and their ready availability. The potentially less durable vitreous silicate ceramics are more common and more easily fabricated as monoliths due to lower processing temperatures, and may prove useful as well, although they suffer from typically low thermal conductivities (of the order of $2 \mathrm{~W} / \mathrm{m}^{\circ} \mathrm{K}$ ). Table 1 presents some relevant properties of ceramic materials under consideration, as reported in the literature. Properties of 304L stainless steel are included for comparison purposes.

Other ceramic materials also have physical properties that could be applied to the storage of nuclear waste, including beryllia, and various nitrides, oxynitrides and carbides. $-5-$

9/23/94

$\mathrm{K}$. Wilfinger 
Pound for pound, these are significantly more expensive. Beryllia for instance, can be hundreds of times more expensive than alumina to process, and it poses a large toxicity problem as well. The processing and cost disadvantages seem to outweigh the fact that beryllia has a much higher thermal conductivity than other ceramics (and many metals). Non-oxides tend to require special atmospheres for processing.

Ceramic fiber composites generally contain significant porosity and require more complicated forming techniques than conventional monoliths. Although generally stronger and tougher, they may in fact offer decreased resistance to corrosion or provide a ready transport path for moisture. Composite ceramics are, in general, more difficult and expensive to form, and offer no definable advantage in a static, cool and relatively low load application. A possible exception could be the class of transformation toughened particulate composites such as zirconia toughened alumina (ZTA). These are composites at the particulate level, so the processing is little more difficult than for conventional monolithic ceramics. Many of the techniques for working with other types of composites are not well advanced, nor are they supported by the same body of literature as the conventional ceramics. The conventional ceramics should be investigated experimentally before proceeding seriously with the second group.

The major problems associated with forming large, dense, ceramic objects by conventional sintering are related to the initial particle size of the material to be formed, i.e., reducing the particle size promotes sintering and densification while detracting from ease of formation, due to the development of internal stresses. This effect becomes much more noticeable as the size of the object increases. For this reason, fully dense ceramics with little or no glassy phase are typically rather small. Larger objects often contain significant amounts of porosity and/or glassy grain boundary phases. This is in addition to the difficulties imposed by handling large and unwieldy objects, and the relative delicacy of ceramics before firing. Alternative techniques such as thermal spray coating circumvent these processing problems but introduce others

\section{ALUMINA}

The most likely first choice for a ceramic waste container material is aluminum oxide $\left(\mathrm{Al}_{2} \mathrm{O}_{3}\right)$, specifically the alpha phase. It is a light $\left(-3.9 \mathrm{~g} / \mathrm{cm}^{3}\right)$, strong, chemically inert and refractory polycrystalline ceramic. It occurs naturally as the mineral corundum, which shows excellent stability against weathering. Aluminum oxide makes up between 10 and 17 weight percent of the welded tuff found at the repository site [9].

The properties of alumina are well characterized, and several companies have demonstrated the ability to use it to form relatively large, dense and impervious objects. $-6-$

9/23/94

$\mathrm{K}$. Wilfinger 
With proper preparation and facilities, multiple pieces of the ceramic may be routinely joined by brazing, using a bonding glass, or by diffusion bonding. Billets at least six feet tall and five feet in diameter are produced using currently available tooling.

When quenched rapidly, as in thermal spraying, alumina retains a metastable $\gamma$ structure that can subsequently transform to the more common $\alpha$ form on annealing.

Alumina was chosen as the focus of a Swedish waste disposal study that concluded in the early 1980s [10]. A variety of corrosion testing was done on nominally pure, commercially available aluminum oxide, demonstrating that in ground water at moderate $\mathrm{pH}$, alumina corrodes at less than $1 \mathrm{micron} / \mathrm{year}$, probably several orders of magnitude less. Even at the maximum rate, a 1 centimeter thick coating would last something like 10,000 years. Other estimates range into the millions of years.

Alumina ceramics are affected by certain acids (i.e., phosphoric) at low $\mathrm{pH}$ (around $\mathrm{pH} 2$ ), however they are much more resistant than metals under similar conditions. Hydrofluoric acid preferentially attacks the grain boundaries of alumina bodies containing significant glassy phase.

\section{ZIRCONIA}

Partially stabilized zirconia (PSZ) consists of relatively large grains of chemically stabilized cubic zirconia containing many sub-micron precipitates of metastable tetragonal zirconia. Some of the more common stabilizing additions are $\mathrm{Y}_{2} \mathrm{O}_{3}, \mathrm{CaO}$ and $\mathrm{MgO}$ although virtually all of the rare earth oxides can be used to some extent. The unstabilized tetragonal precipitates can be induced to transform martensitically to the less compact, stable monoclinic structure under the influence of a mechanical stress, thereby creating a counter-stress that opposes crack propagation. In some cases, the tetragonal structure may be modified somewhat by heat treatment to provide maximum toughening in the temperature range over which the ceramic is to be used, but for the most part, transformation toughening is a low temperature effect.

Zirconia is slightly stronger and tougher than alumina, but it is also considerably heavier $\left(\sim 5.75 \mathrm{~g} / \mathrm{cm}^{3}\right)$ and generally more expensive. It is less chemically resistant than alumina and more easily reduced, although this should not be a significant problem in the tuff repository environment, which is oxidizing. Zirconia is a very refractory material, with a melting point of approximately $2700^{\circ} \mathrm{C}$, making a dense, sintered product difficult to fabricate. Polycrystalline tetragonal zirconia is chemically similar and potentially much stronger than PSZ, but the technology for fabricating objects with it is substantially less well developed.

$-7-$

$9 / 23 / 94$

$\mathrm{K}$. Wilfinger 
Certain other ceramics, including alumina (ZTA), can be toughened by incorporating micron scale tetragonal zirconia as a discrete second phase, allowing it to act in much the same way as the precipitates in PSZ. This can allow some of the improved properties of a toughened ceramic without paying the full cost penalty of using zirconia alone. In the case of ZTA, density and required firing temperature both increase slightly compared to straight alumina.

\section{SILICON CARBIDE}

Silicon Carbide ( $\mathrm{SiC})$ is a light $\left(3.2 \mathrm{~g} / \mathrm{cm}^{3}\right)$, very strong, tough, refractory ceramic that is chemically resistant in caustic and acidic environments. It is not normally found in nature. Silicon carbide is used primarily for its high temperature strength. It forms a protective $\mathrm{SiO}_{2}$ skin when exposed to high temperatures in an oxidizing atmosphere. Several companies already market single piece $\mathrm{SiC}$ tubes of the order of 10 feet long by approximately 20 inches in diameter, so the required container sizes should be possible, albeit with considerable further development.

Unfortunately, sintered silicon carbide is rather difficult to densify. The large tubes that are presently manufactured normally contain about 15 percent of connected porosity, which would certainly allow the transport of water and water vapor. Some large $\mathrm{SiC}$ parts are manufactured by reaction bonding, which depends on carburizing a metallic silicon bonding phase in a highly reducing environment. Although this results in a part that water will not penetrate, residual metallic silicon may then provide an easier diffusion path or a point of entry for MIC microorganisms. Pure silicon carbide must be sintered in a protective atmosphere at very high temperatures. Lower temperature grades contain significant oxide additions which lead to glassy grain boundaries.

Silicon carbide goes through a reversible $\alpha \Leftrightarrow \beta$ phase transition at around $800^{\circ} \mathrm{C}$, making dense parts subject to cracking during thermal cycling. At room temperature, silicon carbide usually consists of a mixture of the $\alpha$ and $\beta$ phases, due to a combination of particle size and impurity effects. This leads to extreme variability in thermal conductivity, which range from 21 to about $165 \mathrm{~W} / \mathrm{mK}$. It also complicates the issue of bonding between segments. Achieving gas-tight seals on $\mathrm{SiC}$ parts this size would therefore be considered a significant development.

\section{SILICATE MATERIALS}

There are a large number of possible silicate compositions with widely varying behavior. It is impossible to list all the possibilities, much less to describe them. The largest volumes of all ceramic materials manufactured have a silicate component. A few

$-8-$ 
worth mentioning are silica $\left(\mathrm{SiO}_{2}\right)$, mullite $\left(3 \mathrm{Al}_{2} \mathrm{O}_{3} \cdot \mathrm{SiO}_{2}\right)$, forsterite $\left(2 \mathrm{MgO} \cdot \mathrm{SiO}_{2}\right)$ and cordierite ( $\left.2 \mathrm{MgO} \cdot 2 \mathrm{Al}_{2} \mathrm{O}_{3} \cdot 5 \mathrm{SiO}_{2}\right)$, all of which are stoichiometric phases with commercial significance. Most silicates tend to have a significant vitreous (glassy) component and a low thermal conductivity, on the order of $5 \mathrm{~W} / \mathrm{mK}$.

Alumina, magnesia and boria are typical additions which make for more refractory and chemically resistant glasses, although many other materials can be used to tailor the physical properties as well. Structurally, the silicates range from glasses, through dispersed crystals in a glassy matrix and continuous polycrystalline materials with a glassy grain boundary phase to almost wholly crystalline materials. The tuffaceous rock at the Yucca Mountain repository site is 68 to 75 percent silica by weight [9].

The presence of a glassy phase offers considerable advantages in ease of forming dense, impervious ceramics and reducing processing temperatures. Although this is not the rule, certain silicate glasses will flow at temperatures lower than $400^{\circ} \mathrm{C}$. Such compositions are not very chemically resistant however. A glassy phase can also reduce mechanical strength and toughness, more or less in direct proportion to the amount of glass. In view of the repository conditions that currently exist at Yucca Mountain, compositions with even large amounts of glass could probably still make effective coatings or liners for metallic containers, assuming that thermal conductivity issues can be overcome.

\section{SPINEL}

There are a variety of useful, structurally similar, mixed oxide ceramic materials that fall into the category called spinels. They exhibit a wide variety of properties and are often used in electronic ceramic applications. However, one in particular, magnesium aluminate $\left(\mathrm{MgAl}_{2} \mathrm{O}_{4}\right)$ may be useful in the context of a waste package. In most respects, the properties of this spinel resemble those of aluminum oxide. It is slightly more refractory, with a melting temperature of about $2135^{\circ} \mathrm{C}$. It is more expensive to manufacture in a pure form. It differs from alumina in one very important way, however: it is not subject to the $\gamma \Rightarrow \alpha$ transition after thermal spray. This makes it less subject to cracking during high temperature annealing than an alumina coating. Several thermal spray companies can produce $\mathrm{MgAl}_{2} \mathrm{O}_{4}$ coatings.

\section{GLASS-CERAMICS}

"Glass-ceramic" refers to both a class of materials and a particular type of forming process. The range of glass-ceramics is largely a sub-class of the group of silicates, but exhibiting some unique properties. Early in their processing, glass-ceramic materials are completely glassy, and as such may be worked using conventional glass handling $-9-$ 
techniques such as molding and blowing. The finished shape is then crystallized by proper heat treatment, resulting in a fine grained, polycrystalline ceramic with virtually no porosity and little or no residual glass. After the crystallization, many glass-ceramics are at least twice as strong as glasses of the same composition.

The final properties of glass-ceramics are widely variable, but limited somewhat by the requirement that the entire part must be glassy at some point, restricting the range of possible compositions. The maximum strength of a suitable glass-ceramic would have to be evaluated, since flexure strengths ranging from 70-350 MPa have been reported for commercial compositions. Some formulations available commercially are resistant to aqueous corrosion attack. The other major drawbacks to glass-ceramics are mechanical ones. It is by no means a trivial.problem to construct a thin-walled glass container in the required size range, nor to support it during subsequent heat treatment. However, Corning Glass has expressed a willingness to attempt the construction of vessels of suitable size and shape. One of their groups has recently completed the construction of a $27^{\prime}$ diameter monolithic mirror blank using their ultra low expansion glass. The blank is 9 " thick and weighs approximately 33 tons.

\section{GRAPHITE}

Graphite has previously been considered as a medium for radioactive waste disposal. Commercial graphite consists of crystalline graphite in an amorphous carbon matrix. Current technology allows it to be molded and extruded in large sizes. Extruded graphite logs some $6^{\prime}$ long by $3^{\prime}$ in diameter are currently produced as a standard size by several firms. Union Carbide product literature states that $73^{\prime \prime}$ diameters are possible as a special order. Molded blocks are occasionally made even larger. There is no intrinsic reason why this material could not be made in longer sections.

Commercial graphite is both typically porous (generally around $80 \%$ dense with a maximum below $92 \%$ of theoretical density) and structurally weak. Fracture strengths below $4 \mathrm{ksi}$ are normal. Graphite can be rendered gas tight and impermeable, but this requires a large scale chemical vapor deposition process to fill the pores with silicon carbide. Graphite is subject to swelling in high neutron fluxes, although the general belief is that this would not pose a problem under proposed repository conditions.

\section{TITANIA}

Titanium dioxide ( $\mathrm{TiO}_{2}$ ) occurs naturally as the minerals rutile and anatase. Sintered ceramics usually take the rutile structure. Titania is a relatively light $\left(\sim 4.26 \mathrm{~g} / \mathrm{cm}^{3}\right)$, moderately strong, chemically inert and moderately refractory polycrystalline ceramic. It

$-10$ 
melts at about $1840^{\circ} \mathrm{C}$ and can be processed at somewhat lower temperatures than alumina but it is also somewhat more expensive. Its thermal expansion is slightly higher than alumina, although some aluminum titanate compositions have low overall thermal expansion. Titania is insoluble in water at neutral or acid $\mathrm{pH}$ but soluble in sulfuric acid or under highly alkaline conditions.

Pure, white titania is used in large quantities as an additive by the paint industry so uniform, high quality powder is readily available. Titania has been suggested as a diffusion bonding agent for the joining of alumina.

\section{CHEMICALLY BONDED CERAMICS}

Chemical set, cementitious ceramics can be used to manufacture large, monolithic objects. These materials undergo chemically triggered crystallization at or near room temperature. Several types are available, including sulfate bonded or phosphate bonded oxides and hydrated calcium-alumino-silicates.

Chemical set ceramics are prepared with an excess of liquid to promote mixing and flow. As such, they are typically rather porous and contain water of hydration that could be driven off at elevated temperatures or possibly in a strong radiation field. Although a few such materials are amenable to complete densification and dehydration during firing, this is not common practice. At least one manufacturer of furnace linings reports the ability to cast structures up to 22' long by 8' square which are then fired to increase structural strength prior to shipment. Even so, these structures remain about $15 \%$ porous, sufficient for transport of water.

\section{Forming Routes}

The selection of forming route is largely governed by the specific ceramic material in question. Ceramic parts for nuclear waste containers could be fabricated in a number of different ways, each with several potential alternatives for some of the individual steps. If made a suitable size, one part might make up the entire waste container, or if this is undesirable for economic or technical reasons, several smaller parts could be joined together. Subsequently shrink fitting a metal shell around the ceramic container would greatly improve the impact resistance and strength of either a monolithic or assembled package.

Free-standing bulk parts would most likely be manufactured by "traditional" processing, consisting of powder consolidation by some technique such as casting, pressing or extrusion, followed by sintering at elevated temperatures. Modern "spray-up" techniques might also be used for fabrication of monoliths. This practice is not currently

$-11-$

9/23/94

$\mathrm{K}$. Wilfinger 
very common, but has been used to make cylindrical objects $5^{\prime}$ in diameter or more than 10 ' long.

\section{Extrusion}

Extrusion is used to produce lengths of vitreous ceramic sewer pipe at least six' long by $42 "$ in diameter. While parts this large are typically made of low firing clay ceramics, there are no intrinsic reasons why other materials should not be processed this way as well. Production of large sections of commercial "graphite" involves extrusion and firing of carbon, sometimes in billets several feet in diameter. There is a possibility that existing extruded ceramic compositions could provide adequate protection against the type of environment expected at Yucca Mountain, however the raw materials have substantial variability in purity.

\section{Slip Casting}

Slip casting of powder suspensions in porous molds is used to economically produce large and intricate shapes of ceramic parts for sintering. The conventional whitewares industry (i.e. toilets and tanks) is almost wholly dependent on slip casting for production. Alumina tubes several inches in diameter by ten feet or more in length are commonly produced by slip casting. The large sizes of $\mathrm{SiC}$ tubes mentioned earlier are produced this way. There is some difficulty encountered in slip casting large objects in many materials, due to differences in particle morphology, the inavailability of appropriate surface active materials to aid in dispersion and the development of internal stresses during casting. Extremely thick walls and large expanses of material pose a particular problem.

\section{Pressing}

Pressing operations involve the compaction of fairly dry powders into a coherent mass under pressure, typically 3000 psi or greater. This is done along a single axis using mechanical rams, or from all directions using hydrostatic pressure. Although there is some problem with density gradients, large, bulky parts are routinely fabricated using pressing operations. Some companies address this issue by making compositions with binary particle size distributions for a higher and more uniform packing density. WESGO Technical Ceramics has produced alumina structures more than $8^{\prime}$ long and several feet in diameter by joining somewhat shorter pressed units together. Even larger sizes will be possible given the construction of larger tooling. 
The techniques mentioned above produce parts which must subsequently undergo firing in order to develop mechanical integrity. These parts may also require machining operations, before and/or after firing. As formed, they are generally weak and friable. This often presents great problems in transportation and handling, especially for objects large enough to be damaged under their own weight. Additions of organic binder materials for green (unfired) strength are routine, but require careful burn-out during firing, or else can result in fracture, entrapped contamination and excess porosity. Difficulties are also encountered due to non-uniformity of temperature in furnaces of large volume, and of the availability of furnaces with both the large capacity and the high temperature capability required to sinter very large pieces of the more refractory materials.

The type of atmosphere in which sintering takes place may be varied, as can mechanical or atmospheric pressure on the part. Hot isostatic pressing (HIPing) is a process that combines high temperatures with high pressure to promote rapid densification and bonding and reduce grain growth. HIP furnaces large enough to process individual parts of the size required for this application can be constructed using current technology, however none exist at the present time. The largest currently available is approximately half of the required size. Both National Forge and ABB Autoclave would be willing to quote on a HIP $18^{\prime}$ long by $6^{\prime}$ in diameter that could fire as high as $2000^{\circ} \mathrm{C}$ at $30 \mathrm{ksi}$. Although no formal quotes were obtained, the cost of such a furnace would be quite high, running into the tens of millions of dollars. However, the ceramics most likely to be used in this application can be densified at temperatures below $1600^{\circ} \mathrm{C}$ and pressures around $10 \mathrm{ksi}$, which would allow a significant reduction in the equipment cost.

\section{Fusion Casting}

It is possible to produce large ceramic parts by solidification of materials melted using an electric arc. The resulting fusion-cast ceramic is dense, crystalline and impervious, but must presently be made very thick (minimum of $2 "$ ) and to poor dimensional tolerances. Large grains and structural imperfections are common. Subsequent machining would be both difficult and extremely costly. Due to their "intricate" shape and "thin" walls (Fusion-casting is normally used to produce large refractory blocks for corrosive, high temperature environments such as glass melting tanks), the fusion-cast containers would probably be manufactured in sections and then assembled. A possible exception is fused cast pipe lining, which is accomplished by introducing molten basalt or similar material into a metal pipe spinning about its central axis, leaving a heavy, single piece lining on cooling. 


\section{Enameling}

Glassy (enamel) coatings can be applied by brushing, spraying or dipping a prepared metal substrate in a fluid suspension of enamel powder, followed by heating in a furnace. The enamel particles melt, forming a continuous, hard, glassy layer that is intimately bonded to, and matches the contours of, the substrate. The coating would best be applied to the outside of the vessel, protecting it from the environment; since the enamel provides virtually no support, relying completely on the metal for strength. In any place that the metal fails, the enamel is likely to fail as well. This process is limited to coatings which are low melting compared to the surfaces on which they are applied. The enamel layer must generally be quite thin, or else it is likely to run off during firing, or crack due to the development of thermal stresses. Low melting glasses of this general type are not very chemically resistant compared to other types of ceramics.

\section{Thermal Spray}

Thermal spray coatings are formed by spraying a metal container with ceramic powder melted in an electric arc (plasma spray) or flame (flame spray, HVOF, D-Gun). The molten droplets spread and cool rapidly when they impact the substrate, creating a continuous, solid layer. Thermal spray techniques allow the formation of polycrystalline coatings that are much more refractory than enamels, since the substrate does not have to be heated to the melting temperature of the ceramic. The application can be made thicker than a typical enameled coating by making multiple passes over the same area, allowing it to be used either inside or outside a metal structure. Free standing objects of very impressive size have been constructed by spraying up thick layers over a removable mandrel. Radomes some four feet long have been constructed by this method. There continue to be limits on the maximum possible thickness, again due to stress build-up, as well as limits on the mechanical properties achieved.

In general, thermal-sprayed ceramic coatings have been typically porous, achieving a maximum of about $90 \%$ of theoretical density. These coatings are readily subject to penetration by moisture. Recently though, with the advent of high velocity oxyfuel (HVOF) and detonation (D-gun) type sprayers, manufacturers have begun to claim densities in the range of $98-100 \%$ of theoretical density, even for refractory ceramic materials. Lower melting formulations tend to have the lowest porosity, but at the expense of a reduction in material properties. Although zirconia can be thermal-sprayed, it typically does not approach full density because it is so refractory. The density of all thermally sprayed coatings can be improved by careful control of feed stock and spraying conditions, but complete melting of the sprayed particulates is a requirement for the densest coatings.

$-14-$

9/23/94

$\mathrm{K}$. Wilfinger 
A potential problem is brought about by the rapid quenching of the sprayed droplets, sometimes resulting in metastable phases. Alumina for instance, does not generally solidify to the alpha structure on rapid cooling, but rather forms the transitional gamma phase. This results in greatly reduced thermal conductivity. Subsequent transition to the alpha form results from reheating above $1000^{\circ} \mathrm{C}$, leaving a more compact structure than the gamma phase. Post coating heat/pressure treatments are sometimes used to densify thermally sprayed ceramic coatings, but as with the enamels, the substrate properties determine the maximum temperature to which the coated object can be heated.

In most applications, coatings are considered "thick" when they exceed one millimeter, however free standing structures up to 80 millimeters thick have been made successfully. Some coatings can be pre-stressed thermally to make them more resistant to inadvertent damage. Robotic systems can be constructed to apply coatings to the interior or exterior of large vessels. Sealing of an interior lining remains an issue, while an exterior coating on a metal vessel could be made to provide a "seamless". closure. A very few manufacturer's claim to be able to lay down coatings of alpha alumina rather than the gamma phase normally resulting from thermal spray techniques, but this should be confirmed independently.

A variation on this technique allows the formation of single piece bulk parts over removable mandrels by thermal spraying. The parts are formed at about 90 percent of full density, making them strong and easy to handle, even in large sizes. They may then be sintered or encapsulated and pressed isostatically at high temperature (HIP) in order to eliminate porosity and complete the densification process. This technique is used on a small scale domestically by Technetics Inc. and on a large scale by LWK-Plasmakeramik GMBH in Germany, and developmental projects have been carried out by a number of other firms.

\section{Spin Casting}

A glass liner can be applied to a metallic waste container as a separate part or by spin-casting, which in this case consists of pouring molten glass into the metal shell, and then spinning the shell at high speed around its central axis. The molten glass is spread throughout the container by centripetal acceleration, and then allowed to cool. Certain chemical reaction vessels are constructed this way. By preheating the substrate and taking account of the relative thermal expansions of glass and metal, the glass liner is put in compression. The spun glass liner has many of the qualities of an enamel coating, including the intimate joining and following of contours, but can be made much thicker without fear of run-off. Thermal expansion and thermal shock remain considerations. A 
separately constructed glass liner would have to be made somewhat thicker still in order to survive handling, presenting potential problems with thermal transport.

Several variations on using the spin casting technique to line large metal pipes have been tried with some success. Abresist Corporation sells a variety of pipe lined using melted basalt. A more exotic iteration was demonstrated in the late 1980s by Odowura and Ikenchi, who lined steel pipe with aluminum oxide and iron metal layers produced in-situ by a thermite type redox reaction.

\section{Chemical Vapor Deposition}

Chemical vapor deposition (CVD) can be used to make dense, impervious ceramic coatings of a variety of materials, including titanium carbide, alumina and yttria. This process relies on the thermal decomposition of complex and sometimes hazardous gases, which then react to form the coating on the substrate. Although adaptable for use in closed containers, CVD is a not normally applied to coating large objects, and would not be a first choice for protecting containers that could be coated more easily by other means. A particular disadvantage is the need to heat the substrate to high temperatures, in order to form a strongly bonded coating, which may lead to problems when coating metals with refractory ceramics.

A CVD process would be required to fabricate impervious graphite containers of large size by gas phase infiltration and subsequent decomposition and reaction. This type of CVD could be used to densify or seal other porous ceramic structures as well, but there will almost certainly be some remaining interconnected porosity, making for a barrier considerably shorter than the apparent wall thickness. CVD is probably not a reasonable alternative for the construction of large ceramic waste containers.

\section{Explosive Forming}

Explosives have been used in some cases to project powdered materials toward surfaces at high velocity, causing the powders to deform and bond upon impact. The particulates are heated by the explosion and by friction forces on impact. Explosive forming has been used to promote rapid densification of "exotic" materials, and perhaps in other applications as well. At present, it is not a particularly reliable technique for producing impervious, uniform materials, nor for bulk forming. It can be readily discounted as a potential forming route for ceramic waste containers. A related device is the Detonation gun, which is a fuel fired thermal spray device that projects molten powders toward an intended target at explosive velocities. 
Joining

The various coating techniques mentioned above could be used to produce continuous, seamless, inner or outer linings for metallic waste containers. After the overpack was filled, it would still have to be capped and sealed by some method that prevents water penetration, escape of gases, etc. This applies to ceramic containers produced by bulk forming techniques as well, and might also be required to assemble such containers from smaller pieces. In most cases, the joint would not have the same properties as the rest of the material being joined. Credit may be taken only for the weakest link in any barrier. The joint associated with final closure must be made and inspected remotely in a radiation hot cell. This presents the most difficult technical issue in the construction of a ceramic waste barrier.

Unlike metals, ceramic materials cannot normally be welded using an arc, flame or laser. Although they can certainly be melted, the material near the melted region is subject to fracture under the extreme thermal gradient and resulting stresses imposed by the welding process. Only a few ultra-low expansion crystalline materials can be joined this way. Low expansion, glassy materials such as fused silica can be welded with proper care, particularly in thin sections. The result is that a strong, impervious joint is often much more complex to manufacture for ceramic parts than for metals.

\section{Mechanical Joints}

The first type of joint to consider is a purely mechanical connection. This includes threaded and pin type closures, flanges which may be held together by clamps or crimped metal bands, and shrink fit, press fit and butt-type joints that rely on bolting or welding of an outer metal casing for strength. Only the last of these would normally result in a reliable air or liquid-tight seal without extensive surface machining, and that would be due to continuity of the metal, not the ceramic.

It might be possible to include a flexible polymeric gasket to promote sealing, but these would be expected to degrade rapidly in the repository environment. Even soft metallic gaskets could eventually begin to leak, particularly if affected by MIC. Mechanical joints and closures that require extensive machining would greatly increase the difficulty and cost of assembly and so should be avoided if possible. This is particularly true for containers that must be assembled from smaller sections, due to the large number of joints which would have to be machined. 


\section{Solder Glasses}

Low temperature "solder" glasses can be used to join more refractory ceramics with a vitreous, airtight bond. The parts to be joined must fit together well, but not necessarily perfectly, since the glass flows and fills the joint. The solder glass will typically be weaker and less chemically resistant than the parts being joined, however, if the number of joints is minimized, and each covers a fairly broad surface, solder glasses could provide excellent sealing for ceramic containers supported by metal substrates.

A variation on the solder glass joint involves reheating an enameled container sufficiently to soften the enamel and allow it to flow, thereby fusing the lid to the body of the container. This has the benefit of simplifying the container chemistry, and provides a joint with the same properties as the rest of the lining. A major disadvantage is that the contents of the waste container could be exposed to unacceptable temperatures during the sealing process. A possible solution to this problem is the use of localized heating to complete the closure, but this can lead back to thermal shock issues.

\section{Brazes}

A "brazed" metallic bond can be made between parts in much the same way as a glassy bond. Brazing is normally used to make ceramic to metal joints, but can be used to make ceramic to ceramic joints as well. Brazes ranging from low melting indium metal alloys to much more refractory molybdenum-manganese compositions are possible, but are rarely produced over extremely large surfaces. Typical requirements are a close mechanical fit between parts (often obtained by machining), the application of a metallization layer to prepare the surface for bonding and a reducing atmosphere for firing. On a unit area basis, brazed joints are probably somewhat stronger than comparable solder glass joints, but the two would normally have different physical configurations. There is a possibility that the braze could be completed using the heat of a torch or laser progressing in linear fashion along the surface of the joint, thereby minimizing the temperature rise seen by the package as a whole. This variation is not normally applied to ceramics, for the same reason that welding is not, and so would require development. It is not as severe a problem as welding though, due to the lower temperatures and reduced thermal gradient required for brazing. A recent development of sodium zirconium phosphate (NZP) ceramics at Argonne National Lab suggests that a laser brazed joint is possible in certain cases.

There are two additional difficulties associated with brazed joints that may make them unsuitable for use in the repository environment. First, they may be susceptible to MIC corrosion processes and so would pose a weak link in the corrosion resistant barrier. 
Second, they could be inhomogenous, which might make them subject to corrosion due to galvanic processes.

\section{Diffusion Bonding}

Diffusion bonding is a process that may be used to join carefully matched surfaces on polycrystalline materials by actually growing crystals across the interface. It requires a tight fit between parts, the application of mechanical pressures and high temperatures roughly comparable to the normal sintering range of the parts being joined. The result is a joint that is nearly identical in character to the bulk of the material. The process is normally applied on a much smaller scale than this application demands, so the equipment required would be quite large and expensive. Because of the high bonding temperatures, this process would likely be unsuitable for completing the closure of a container, but would rather be better suited to the assembly of individually processed bulk parts into larger units.

The Swedish work in nuclear waste containment during the early 1980 s used a variation of this method to complete closure. In that instance, $\mathrm{TiO}_{2}$ powder was introduced between the alumina sections in order to provide a somewhat lower temperature diffusion bond. Large thermal gradients and resultant stresses led to stress induced cracking and termination of that project. Another possible iteration of this approach would involve the insitu oxidation of a titanium metal layer during the diffusion bonding process.

\section{Cements}

A cemented closure might be sufficient to seal a ceramic waste container that is supported within a metal shell. There is a variety of silicate and phosphate based cements commercially available for joining, sealing and lining refractory ceramic constructions. These materials are designed for much harsher thermal environments than are expected in the tuff repository, and so should show excellent durability. They are relatively weak, however, and require water or other liquid carrier which would have to be removed during setting. Depending on how the cements are applied, residual porosity can range from roughly two to as high as fifteen percent, sufficient to pass moisture or gases. Unless they are fully cured at elevated temperatures, these materials would be expected to give up their moisture over time, creating an undesirable situation within the waste package.

\section{Sol gels}

The sol-gel technique for chemically producing "high-melting" glasses at relatively low temperatures has been applied to the sealing of small electronic components. Temperatures of several hundred degrees Celsius are still required however, in order to $-19-$ 
drive off organic residues and eliminate porosity from the gel. It might be possible to accomplish this with localized heating as mentioned under solder glasses, but sol-gel materials are quite subject to cracking during drying and densification (which typically should be slower than would be possible on a hot waste container). Once the densification process is complete, the gel derived glasses have identical properties to glasses of the same composition produced by other means, so that the container would then have to be heated to higher temperatures to ensure a reliable seal. The level of development in sol-gel technology is such that it probably will not be of much use in this application.

\section{Conclusions}

It will be possible to fabricate ceramic or ceramic-metal nuclear waste containers for the Yucca Mountain repository by any of several currently available techniques, and using any of several ceramic materials. Even so, a minimum of three (and more likely five or six) years of development time will be required to learn to reliably fabricate such large structures, irrespective of the specific material and forming routes. Dense aluminum oxide currently offers the most attractive combination of cost, thermal conductivity, chemical resistance, strength and manufacturability. Although they are less chemically resistant, high alumina, vitreous bonded ceramics would be less expensive than completely crystalline, sintered ceramics and may prove to be almost as durable in this context. Thermal conductivity may be the limiting factor in their use.

Closure techniques for extremely large ceramic containers are as yet unproven, especially since this task must be accomplished remotely in a hot cell. Experimental verification of appropriate properties will be required to determine which of the available techniques can be used in this context.

Because of their brittle nature, ceramics will probably be used in conjunction with metals in order to best fulfill waste package design requirements. The most likely approaches are:

(1) To produce self-supporting, impervious ceramic liners for a metallic shell using cold isostatic pressed, green machined blocks that would then be sintered and diffusion bonded. Closure would be accomplished mechanically, in conjunction with a thermal sprayed outer coating to develop an acceptable seal. Metallizations and brazes could be used instead, but credit for performance will be limited to the properties of the closure material. 
(2) To thermal spray coat a metal container with a relatively thin, dense ceramic layer that should prevent it from corroding under repository conditions. Magnesium aluminate spinel offers most of the benefits of alumina in this application, but is not subject to thermal transformation. This type of construction probably poses the least overall risk of failure. Modern thermal spray techniques could also allow the fabrication of free standing or coated ceramic waste containers using a single basic process and may allow a "seamless" method to accomplish final closure. 


\section{SELECTED REFERENCES}

[1] "Preclosure Analysis of Conceptual Waste Package Designs for a Nuclear Waste Repository in Tuff," W.C. O'Neal, D.W. Gregg, J.N. Hockman, E.W. Russell, and W. Stein, UCRL-53595, November, 1984.

[2] "Design of a Nuclear Waste Package for Emplacement in Tuff," W.C. O'Neal, A.J. Rothman, D.W. Gregg, J.N. Nockman, M.A. Revelli, E. W. Russell, and J.R. Schornhorst, UCRL-88192, February 1983.

[3] "Selection of Candidate Canister Materials for High-Level Nuclear Waste Containment in a Tuff Repository," R.D. McCright, H. Weiss, M.C. Juhas, and R.W. Logan, UCRL-89988, 1984.

[4] "Electrochemical Determination of the Corrosion Behavior of Candidate Alloys Proposed for Containment of High Level Nuclear Waste in Tuff," Robert S. Glass, George E. Overturf, Robert E. Garrison, and R. Daniel McCright, UCID-20174, 1984.

[5] "Corrosion Performance of Metals and Alloys in a Tuff Geochemical Environment," R.A. VanKonynenburg and R. D. McCright, UCRL-91740, October 1983.

[6] "Containment Barrier Metals for High Level Waste Packages in a Tuff Repository," E. W. Russell, R.D. McCright and W.C. O'Neal, UCRL-53449, October 1983.

[7] "FY85 Status Report on Feasibility Assessment of Copper-Base Waste Package Container Materials in a Tuff Repository," R.D. McCright, UCID-20509, September 1985.

[8] "Thermal Analysis of NNWSI Conceptual Waste Package Designs," W. Stein, J.N. Hockman, and W.C. O'Neal, UCID-20291, 1984.

[9] "Evaluation of Tuff as a Medium for a Nuclear Waste Repository: Interim Status Report on the Properties of Tuff," J.K. Johnstone and K. Wolfsberg, SAND-80$1464,1981$.

[10] "Aluminum Oxide as an Encapsulation Material for Unreprocessed Nuclear Fuel Waste- Evaluation from the Viewpoint of Corrosion," Swedish Corrosion Institute, Final Report 1980-03-19.

"Ceramic Composite Piping Produced by a Centrifugal-Exothermic Process," Communications of the American Ceramic Society, April 1986.

"Diffusion Bonding of Ceramics (review), O.M.Akelson, J.Mat.Sci., 27 [3] 56979 (1992).

Corrosion Resistant Ceramics for Severe Environments, Sheppard, Laurel M., Cera.Bull.,70 [7] 1146-1158, 1166 (1991).

Microstructure and Properties of Plasma Ceramics, Ekkehard H. Lutz, J.Am.Ceram.Soc., 77 [5] 1274-80 (1994). 
George Sines and Tatsuo Okada, "Flaws Responsible for Slow Cracking in the Delayed Fracture of Alumina, J.Am.Ceram.Soc., Vol.66, [3] 228-232 (1983).

W.A.Zdaniewski, et. al., "Gamma Radiation effects on the Strength of Borosilicate Glass,"J.Am.Ceram.Soc., 66 [5] pp311-13 (1983).

W.D.Rankin and G.G.Wicks, "Chemical Durability of Savannah River Plant Waste Glass as a Function of Waste Loading," J.Am.Ceram.Soc., 66 [6] pp417-20 (1983).

F.J.Ryerson, F.Bazan and J.H.Campbell, "Dissolution of a Nuclear Waste Ceramic: An Experimental and Modeling Study," J.Am.Ceram.Soc., 66 [6] pp46270 (1983).

Hurlbut, C.S. and Klein, C., Manual of Mineralogy (after James D. Dana), John Wiley and Sons, NY, 1977.

Schwartz, M.M., Ceramic Joining, ASM International, 1990.

Rothenberg, G.B., Refractory Materials, Noyes Data Corporation, NJ, 1976.

Kingery, W.D., Bowen, H.K., Uhlmann, D.R., Introduction to Ceramics, John Wiley and Sons, NY 1976.

"Brazing Strip Eliminates Premetallizing", Product Announcement, Design News, December 1993.

Plasma Flame Shapes Smooth Ceramics", Product Announcement, Materials Progress, November 1993.

Thermal Spray Technology Update, Adv.Mat.Proc., p30-34, May 1994.

Sulfide Ceramics Seal High Temperature Batteries, News Release, Adv.Mat.and Proc., p10., July 1994.

Daniel W. Parker and Gerald L. Kutner, "HVOF Moves into the Industrial Mainstream," Adv.Mat.Proc. pp31-35, July 1994.

"Corning Completes Mirror Blank", News release, Ceramic Industry, p14, July 1994.

"CRADA looks at Joining Ceramics", News release, Ceramic Industry, pp21-22, July 1994.

A.J.Stavros, Praxair Surface Technologies Inc., correspondence, July 8, 1994.

$-23-$

$9 / 23 / 94$

$\mathrm{K}$. Wilfinger 
CONTACTS

ABB Autoclave Systems

3721 Corporate Drive

Columbus, OH 43229

Dick Muzyka

(614) $891-2732$

Abresist Corporation

P.O. Box 38

Urbana, IN 46990

(219) 774-3327

Paul O. Abbe Inc.

243 Center Avenue

Little Falls, NJ 07424

(312) $256-4242$

Alberox Corp.

Industrial Park

New Bedford, MA 02745

Dennis Denoyer

American Valve and Enameling

2855 S. Holt Road

Indianapolis, IN 46241

(317) 241-9279

AREMCO Products

P.O.Box 42

Ossining, NY 10562.

Brenda T. Lyons

AVCO Corp.

Systems Division

201 Lowell St.

Wilmington, MA 01887

(617) $657-4423$

B\&B Refractories, Inc.

12121 Los Nietos Road

Sante Fe Springs, CA 90670

(213) $946-4535$

Batelle Memorial Institute

505 King Avenue

Columbus, $\mathrm{OH} 43201$

(614) 424-6424

Bolt Technical Ceramics

P.O.Box 718

Conroe, TX 77305-0718.

Juergen Ruchoeft

Brunswick Corp.

Defense Division

Neal Caterdale

(703) 783-3121

$-24-$

$9 / 23 / 94$

$\mathrm{K}$. Wilfinger 
Carborundum Corp.

Monofrax Plant

501 New York Avenue

Falconer, NY 14733

(716) 483-7200

Frank Knee

Ceradyne, Inc.

3169-A Red Hill Avenue

Costa Mesa, CA 92626

Douglas Brown

(714) 549-0421

Coors Ceramics Company

Structural Division

600 Ninth Street

Golden, CO 80401

(303) 277-4453

Michael Chipman

Corning Glass Works

Sullivan Park FR-6

Corning, NY 14831

(607) 974-3438

Fred Quan

Ceram-Tek

981 W. 18th Street, Box 1437

Costa Mesa, CA 92626

(714) $969-4787$

Ceramic Coating Company

Box 370

Newport, KY 41072

(606) $781-1915$

Don Kropp, George Benson

Champion Spark Plug

Ceramic Division

20000 Conner Avenue

Detroit, MI 48234

(303) $891-4040$

Cleveland Quarries Co.

Box 261

Amherst, $\mathrm{OH} 44001$

(216) $986-4501$

Consolidated Ceramic Products

838 Cherry Street

Blanchester, $\mathrm{OH} 45107$

(513) $783-2824$

DFC Ceramics Inc.

515 S. Ninth Street, Box 110

Canon City, CO 81212

Tom Hart

(303) $275-7525$

W. S. Dickey Co.

824-826 E. 4th Street, Box 6

Pittsburgh, KS 66762

John Underecker

(316) $231-1400$

$-25-$

9/23/94

$\mathrm{K}$. Wilfinger 
Eagle-Picher Industries, Inc.

Specialty Materials Division

Box 798

Quapaw, OK 74363

Jim Everett, Frank Valent

(918) 673-2201

Electro-Coatings

893 Carlton Street

Berkeley, CA

(415) $849-4075$

Ben Leedel

Ervite Corp.

Box 8287

Erie, PA 16505

(814) $838-1911$

Exxon Research and Engineering

Materials and Heat Transfer Division

Florham, Park, NJ 07932

Joe Lewandowsky

(201) 730-2935

Fels Refractories, Inc.

1133 Inmam Avenue

Edison, NJ 08820

(201) 757-0767

Ferro Corp.

Coatings Division

4150 E. 56th Street, Box 6550

Cleveland, $\mathrm{OH} 44101$

(216) $641-8580$

Findlay Refractories Co.

Box 517

Washington, PA 15301

(412) $225-4400$

Frenchtown Ceramics Co.

Eighth and Harrison Streets

Frenchtown, NM 08825

(201) 996-2121

General Ceramics

National Beryllia Division

Haskell, NJ 07420

Jack Cook

(201) $839-1600$

W.R. Grace and Company

Box 2117

Baltimore, MD 21203

Robert Morgan

(301) $531-4146$

Greenleaf Corporation

Technical Ceramics Division

25019 Viking Street

Hayward, CA 94545

Robert Morgan

(510) 783-0120

$-26-$

9/23/94

$\mathrm{K}$. Wilfinger 
Heany-Hartstoffe, Inc.

Fairview Drive, Box 38

Scottsville, NY 14546

(716) $889-2708$

Industrial Materials Technology

155 River Street, Box 565

Andover, MA 01810

(617) $470-1620$

International Pressure Glass Co.

P.O. Box 686

Urbana, $\mathrm{OH} 43078$

Cliff Orcutt

(513) 653-8152

Ipsen Ceramics

325 John St.

P.O. Box 420

Pecatonia, Ill 61063-0420

Mike McGarry

(815) 239-2385

Lab-Crest Scientific Glass Co.

E. County Line Road

Warminster, PA 18974

(215) 674-6600

Lucas-Milhaupt

5656 S. Pennsylvania Avenue

Cudahy, WI 53110

Jerry Bassalyga

METCO

1101 Prospect Avenue

Westbury, NY 11590

Frank Longo

Miller Thermal Technologies

Plasmadyne Division

2601 Walnut Avenue

Tustin, CA 92680

Amos Bernstein

(714) $731-2900$

Mobay Chemical Corporation

Pemco Division

5601 Eastern Avenue

Baltimore, MD 21224-2791

Cliff Jett

(414) $843-8300$

National Forge Engineered Systems

155 River Street

Andover, MA 01810

Jan Sommer

$(508-470-1620)$

Norton Company

1 New Bond Street

Worcester, MA 01606-2698

Ed Hamel

$-27-$

$9 / 23 / 94$

$\mathrm{K}$. Wilfinger

(301) 633-9550

(508) $795-2488$ 
Nuclear and Aerospace Material Company

16716 Martencoit Road

Poway, CA 92064

(619) 487-0325

Ed Engle

Praxair Surface Technologies

1500 Polco St.

Indianapolis, IN 46224

(317) $240-2444$

A.J. Stavros

Sauereisen Cements Co.

RIDC Park, 160 Gamma Drive

Pittsburg, PA 15238

Kurt Zimmer

(412) 963-0303

Schott Glass Technologies

400 York Avenue

Duryea, PA 18642

(717) $457-7485$

Sohio Engineered Materials

(Carborundum)

Box 156

Niagara Falls, NY 14302

(716) $278-2000$

Southwestern Porcelain, Inc.

Box 8

Sand Springs, OK 74063

(918) $245-1375$

Superior Graphite

120 South Riverside Plaza

Chicago, Il 60606

Dave Laughton

(312) 559-2999

Technetics Corp.

1600 Industrial Drive

DeLand, FL 32724

(904) 736-7373

Technology, Inc.

Industrial Products Division

335 N. Griffin Street

Grand Haven, MI 49417

(616) 846-2020

Universal Clay Products Co.

Box 1631

Sandusky, $\mathrm{OH} 44870$

(419) $626-4912$

Varian Associates

EIMAC Division

301 Industrial Way

San Carlos, CA 94070

(415) $592-1221$

$-28-$

9/23/94

$\mathrm{K}$. Wilfinger 
Watkins Brick Co., Inc.

Box B, Ensley Station

Birmingham, AL 35218

(205) 786-4318

WESGO Technical Ceramics

477 Harbor Blvd.

Belmont, CA 94002

(415) 598-3313

P.C.Smith 
Table 1 - Engineering Properties of Some Ceramic Materials and 304L Stainless Steel

$$
\text { SiC }
$$
$\mathrm{Al}_{2} \mathrm{O}_{3} \quad \mathrm{ZrO}_{2}$

$\mathrm{TiO}_{2}$ 3041

Specific Gravity

$$
3.2
$$

3.97

$5.6-5.9$

4.26

8.02

Thermal Conductivity $(\mathrm{W} / \mathrm{mK})$ at $400 \mathrm{~K}$

$\begin{array}{lllll}21-155 & 27.2 & 1.8-2.2 & 8.8 & 17.0\end{array}$

Thermal Expansion $\left(10^{-6} / \mathrm{C}\right)$

3.7

8.1

13.1

9.4

17.3

Flexure Strength (MPa)

400

300

$300-400$

69-103

82 (Yield) 550 (Ultimate)

Melting Point

2700

2015

2700

1840

1427

Elastic Modulus (GPa)

$207-483 \quad 380$

205

283

190

Fracture Toughness $\left(\mathrm{MN} / \mathrm{m}^{3 / 2}\right)$

6

3

4.5

2.5

25 